\title{
Experimental Study of Mechanical Strength of the Iron Mixed Concrete
}

\author{
A. Malliha \\ Lecturer (Senior Grade) Civil, Architecture Department, \\ Ayya Nadar Janaki Ammal Polytechnic College, Sivakasi, Tamil Nadu, India
}

\begin{abstract}
Rational use of highly dispersed metal waste is an important issue of material science and environment protection. The quantity of the powdered metallic materials used in industry is steadily increasing; they are especially widely used in the enterprises producing iron powders, in metal sheet production, as well as in abrasive machining. This paper presents an analysis of several kinds of metal waste such as iron and steel powders, mill scales, steel punching, metal shavings and other iron-containing waste from mechanical engineering and metallurgy industries, and the possibility of their use in the manufacturing of concrete products like fillers. This study investigates properties of the samples of the concrete manufactured using highly dispersed metallic fillers. The highest density obtained is in the range of 4000 $4500 \mathrm{~kg} / \mathrm{m} 3$. The common characteristics of the aforementioned materials are their low cost, availability and thus the potential for large production volumes, need for recycling, and tendency to further oxidation and corrosion.
\end{abstract}

Keywords: metal fillers, heavy concrete, metal powders, metal dust, mill scale, steel punching

\section{INTRODUCTION}

A broad study of heavy concrete manufactured with iron inclusions commenced after the scientific publication "Strength and Fracture Toughness of Heavy Concrete with Various Iron Aggregate Inclusions" published in 2004 (Kan, Pie, Chang, 2004). The research in Latvia was launched in 2009 at the Riga Technical University and still is in progress. The result of the investigation at the Institute of Building Production is a patent of the Republic of Latvia LV 14019 B (V. Mironovs, Zemčenkovs, Korjakins, Šahmenko, 2010).
Heavy concrete materials are those with the density greater than $2600 \mathrm{~kg} / \mathrm{m} 3$. In order to achieve higher density traditional fillers of concrete (sand, gravel, crushed rocks) are entirely or partially replaced with other materials with larger specific gravity - e.g., magnetite, hematite, barite, iron and steel powders, mill scales, steel punching, metal shavings etc. For manufacturing heavy and extra heavy concrete the most commonly used material is either Portland cement or alumina cement (Chundelly, Geeno, 2001). Heavy concrete is used for the manufacturing of anchors, pontoons and contra weights, as well as in hydro technical structures and radiation shielding and storage.

In the production of metal powders and their manufactures the waste is generated in different stages - dust particles on the filters, waste on sieves, powders from setting up equipment etc. Rational use of highly dispersed metal waste is an important issue of material science and environment protection. The quantity of the powdered metallic materials used in industry is steadily increasing; they are especially widely used in the enterprises producing powders, in metal sheet production, as well as in abrasive machining.

The common characteristics of the aforementioned materials are their low cost, availability and thus the potential for large production volumes, need for recycling, and tendency of further oxidation and corrosion. Considering the current economic situation in the construction industry in Latvia, economy of resources, reducing consumption of materials, and development of new materials with special properties such as high density and durability are the tasks of major importance. 
International Journal of Trend in Scientific Research and Development (IJTSRD) ISSN: 2456-6470

\section{CHAPTER II}

\subsection{Properties of Iron Containing Concrete Fillers}

\subsubsection{Metal powders}

This study analyzed powders SC100.26 (Fig. 1), MH.80.23 and ASC.100.29 from the Swedish Company Höganäs AB.

The metal powder SC100.26 has the best compressibility of all Höganäs sponge iron powder grades. The green strength is also high. It should be used particularly if high density after single pressing and sintering is desirable. MH80.23 is specially designed to match the requirements for selflubricating bearings. Its range of the particle size is chosen to give an optimum pore structure for this application. The metal powder MH80.23 can also be added to powder mixes in small quantities to substantially improve green strength. The metal powder ASC100.29 is an atomized iron powder with a very high compressibility, which makes it possible to single press compacts with densities of up to 7.2 $\mathrm{g} / \mathrm{cm} 3$. ASC100.29 is particularly suited for high density structural parts and as a base material for soft magnetic applications.

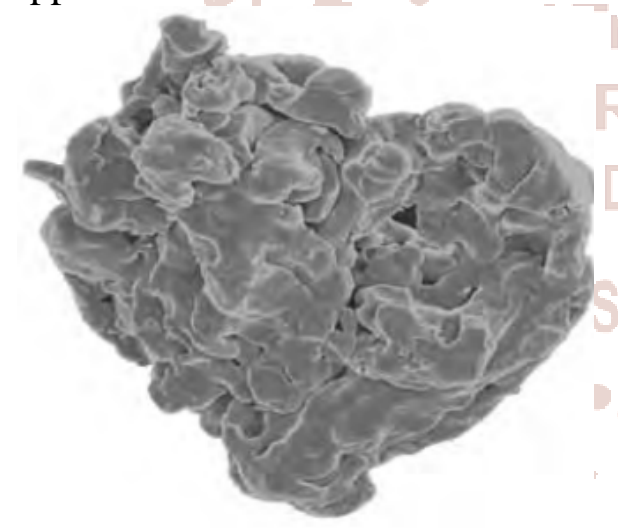

Figure1. Powder SC100.26 microstructure (Average particles size is $\mathbf{4 5}-\mathbf{1 5 0} \boldsymbol{\mu m}$ ).

The iron content in powders is greater than $95 \%$.

The sieve analysis is shown in Fig. 2.

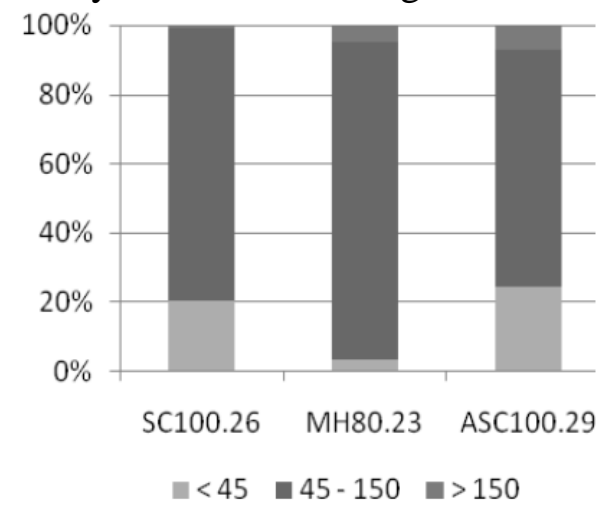

Figure 2: Sieve analysis, $\mu \mathrm{m}$.

\begin{tabular}{|c|c|c|}
\hline Metal powder & AD, g/cm3 & AD, g/cm3 \\
\hline SC100.26 & 2.68 & 29 \\
\hline MH80.23 & 2.30 & 34 \\
\hline ASC 100.29 & 2.98 & 24 \\
\hline
\end{tabular}

Table 1: Apparent density and flow of metal powders

\subsubsection{Metal dust}

Air filters in manufacturing enterprises collect large amounts of dust. The Swedish company HöganäsAB delivers this waste material to consumers under the brand CMS (Fig. 3).

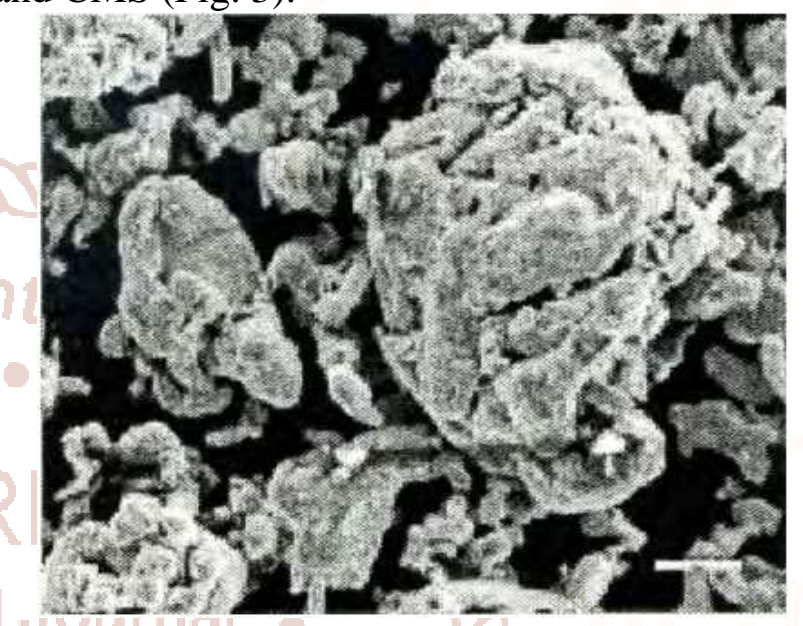

Figure 3: Microstructure of CMS

\begin{tabular}{|c|c|c|c|}
\hline & $<45, \mu \mathrm{m}$ & $\mathbf{4 5 < 2 1 2 , \mu \mathrm { m }}$ & $\mathbf{2 1 2}, \mathrm{um}$ \\
\hline Test results & $56.8 \%$ & $43.2 \%$ & $0.0 \%$ \\
\hline Min & $35.0 \%$ & & \\
\hline Max & & & $1.5 \%$ \\
\hline
\end{tabular}

Table 2: Sieve analysis of powder CMS 95

The product has high iron content (guaranteed over90\%), and its sieve analysis is shown in Table 2.

\subsubsection{Mill scales}

Mill scale is flaky dross obtained in rolling red hot steel or in steel mills. The thickness of the dross layer is approximately $10-15$ microns. The main components of iron dross are $\mathrm{Fe} 2 \mathrm{O} 3$ (hematite), $\mathrm{Fe} 3 \mathrm{O} 4$ (magnetite) and $\mathrm{FeO}$. The properties of iron oxides are shown in Table 3.

\begin{tabular}{|c|c|c|c|}
\hline & $\mathrm{FeO}$ & $\mathrm{Fe} 304$ & $\mathrm{Fe} 203$ \\
\hline Molar mass,g/mol & 71.84 & 231.52 & 159.68 \\
\hline $\begin{array}{c}\text { Specific gravity, } \\
\text { g/cm3 }\end{array}$ & 5.28 & 5.20 & 5.12 \\
\hline Hardness, HV & $270-350$ & $420-500$ & 1030 \\
\hline $\begin{array}{c}\text { Part of mass in } \\
\text { mill scale }\end{array}$ & $50 \%$ & $40 \%$ & $10 \%$ \\
\hline
\end{tabular}

Table 3: Properties of iron oxides 
International Journal of Trend in Scientific Research and Development (IJTSRD) ISSN: 2456-6470

The study used mill scale from the rolling of steel reinforcement supplied by "Liepajas Metalurgs" (Latvia). The particles of raw mill scale are shown in Fig. 4.The iron content in the mill scale is greater than $70 \%$, humidity from 1 to $5 \%$ and specific gravity of the material is $5.2 \div 5.5 \mathrm{~g} / \mathrm{cm} 3$.

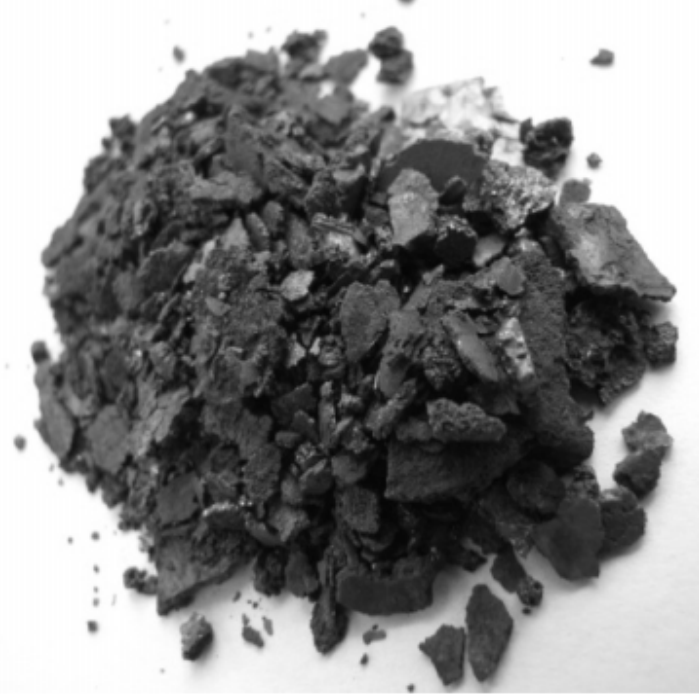

Figure 4: Raw mill scale from JSC "Liepajas Metalurgs".

\begin{tabular}{|c|c|c|}
\hline \multirow{2}{*}{ Particle size, $\mu \mathrm{m}$} & \multicolumn{2}{|c|}{ Grinded Mill Scale } \\
\cline { 2 - 3 } & $30 \mathrm{~s}$ & $120 \mathrm{~s}$ \\
\hline$<063$ & $3.2 \%$ & $9.1 \%$ \\
\hline $63-125$ & $6.3 \%$ & $12.1 \%$ \\
\hline $125-250$ & $16.8 \%$ & $35.4 \%$ \\
\hline $250-500$ & $34.6 \%$ & $35.3 \%$ \\
\hline $500-1000$ & $34.7 \%$ & $8.1 \%$ \\
\hline$>1000$ & $4.4 \%$ & $0.0 \%$ \\
\hline
\end{tabular}

Table 5: Sieve analysis of grinded mill scale

Fig. 5 and Table 5 present the sieve analysis of 30 sand $120 \mathrm{~s}$ grinded mill scales. It was ground in planetary ball mills with nominal speed of $300 \mathrm{rpm}$ (Kazjonovs, Bajare and Korjakins, 2010).

\subsubsection{Steel punching}

One kind of steel scrap is steel punching, which is formed by cutting sheet materials (Fig. 6).

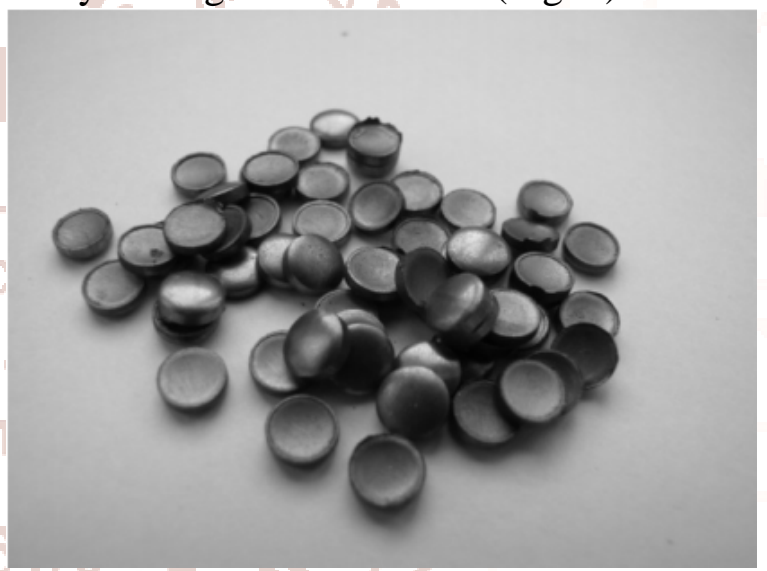

Figure 6: Steel punching from JSC “DITTON

In order to decrease the size of the particles, it is possible to process the raw mill scale. One of the methods is grinding.

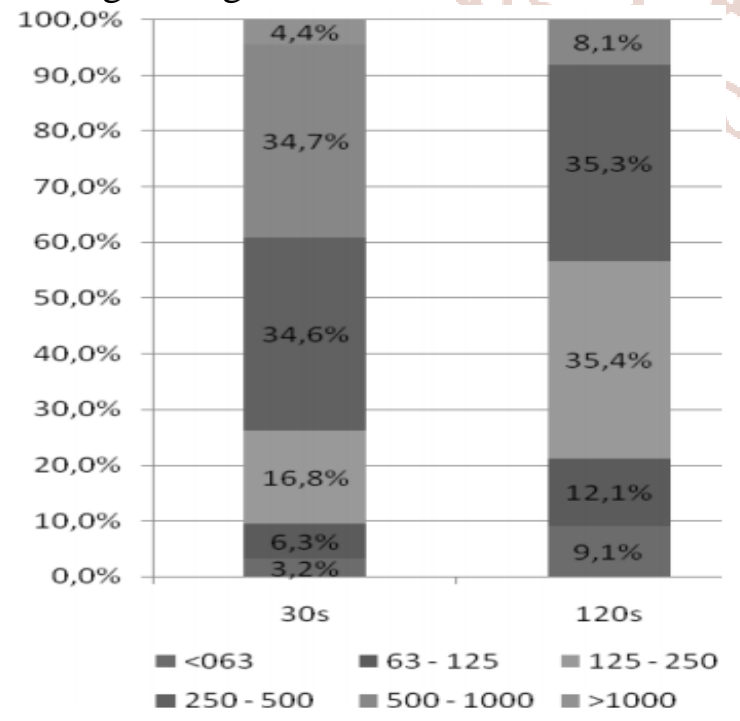

Figure 5: Sieve analysis of grinded mill scale, $\mu \mathrm{m}$.
Driving Chain Factory" (Latvia). Diameter $3.0 \div$ $10.8 \mathrm{~mm}$, height $0.5 \div 3.3 \mathrm{~mm}$. The specific gravity of steel punching is $7800 \mathrm{~kg} / \mathrm{m} 3$.

This research used punching formed by the stamping of circuit elements supplied by the enterprise JSC "DITTON Driving Chain Factory" (Latvia). The cuttings have a round shape andvarious geometric dimensions, the diameter and thickness of the samples are shown in Table 6 . The specific gravity of steel punching is $7800 \mathrm{~kg} / \mathrm{m} 3$.

\begin{tabular}{|c|c|c|c|c|c|c|c|}
\hline \multicolumn{7}{|c|}{ Steel punching types } \\
\hline D,mm & 3.0 & 3.9 & 4.6 & 5.8 & 6.4 & 7.1 & 10.8 \\
\hline H,mm & 0.7 & 0.8 & 0.5 & 1.0 & 1.0 & 2.3 & 3.3 \\
\hline
\end{tabular}

Table 6: The size of steel punching

The investigation of the properties reveals that hardness of the elements is up to $100 \mathrm{HB}$. 
International Journal of Trend in Scientific Research and Development (IJTSRD) ISSN: 2456-6470

\section{HEAVY CONCRETE COMPOSITIONS AND PROPERTIES}

\subsection{Mixture proportioning and preparation}

This study analyzed prepared types of heavy concrete S1 and S2 that are patented in Latvia. The components used in manufacturing heavy concrete and their part of mass are shown in Table 7.

\begin{tabular}{|c|c|c|}
\hline \multirow{2}{*}{ COMIPONENT } & \multicolumn{2}{|c|}{ MIX } \\
\cline { 2 - 3 } & S1 & S2 \\
\hline Cement CEM I 42.5N & 1.00 & 1.00 \\
\hline Mill scale & 3.95 & 3.49 \\
\hline Sand & 0.65 & 0.00 \\
\hline Steel Punching & 0.00 & 2.69 \\
\hline Metal powder & 0.00 & 1.62 \\
\hline Super Plasticizers & 0.015 & 0.016 \\
\hline W/C ratio & 0.55 & 0.62 \\
\hline
\end{tabular}

Table 7: Heavy concrete compositions (by weight)

Several ingredients are prepared before application, e.g., the steel punching is cleaned of oil that is applied in the manufacturing process. The traditional concrete component sand is applied as fine filler in the mix S1. In the second mix S2 all traditional concrete components are replaced with iron containing waste materials.

In order to improve the workability of the mix and reduce $\mathrm{W} / \mathrm{C}$ ratio, a super plasticizer is added in both mixtures. Optimization of packing is applied to decrease $\mathrm{W} / \mathrm{C}$ ratio of the concrete and enlarge its density. Vibration of the concrete is used briefly to avoid the segregation as a result may be issued of metal filler higher specific gravity. Three specimens have been prepared as for compression tests as well for tensile test using each concrete composition S1and S2. To provide detailed properties of the concrete, this study also discusses two heavy concrete types S50 and S100 from the scientific publication "Designing of High Density Concrete by Using Steel Treatment Waste".

\begin{tabular}{|c|c|c|}
\hline \multirow{2}{*}{ Concrete Mix } & \multicolumn{2}{|c|}{$\%$ Aggregate } \\
\cline { 2 - 3 } & S50 & S100 \\
\hline High-weight waste aggregate: & 50 & 100 \\
\hline Iron Dross-Grinded 30 s & 5 & 20 \\
\hline Iron Dross-Grinded 2min & 15 & 20 \\
\hline Mix of steel punching & 30 & 60 \\
\hline Natural aggregate: & 50 & - \\
\hline Gravel & 35 & - \\
\hline Sand & 15 & - \\
\hline
\end{tabular}

Table 8: Details about aggregate proportions
The heavy concrete S50 and S100 and their aggregate proportions are shown in Table 8, the mechanical and physical properties in Table 9 and Table 10 respectively.

\subsection{Properties of mix}

The physical properties of the heavy concrete samples are shown in Table 9. As expected, the iron containing waste materials heighten the density of the product.

\begin{tabular}{|c|c|}
\hline Concrete Type & Density, $\mathrm{kg} / \mathrm{m}^{3}$ \\
\hline S1 & 3200 \\
\hline S2 & 4300 \\
\hline S50 & 3500 \\
\hline S100 & 4600 \\
\hline \multicolumn{2}{|c|}{ Table 9: Physical Properties }
\end{tabular}

The highest density obtained in this study is in the range $4000-4500 \mathrm{~kg} / \mathrm{m} 3$. Also, approximate expenses were estimated for heavy concrete mixtures. The higher density sample had greater expenses mainly due to the metal powder used as fine filler. After 28 days the samples were tested in compression and tension. The results are shown in Table 10.

\begin{tabular}{|c|c|c|}
\hline Concrete Type & $\begin{array}{c}\text { Compressive } \\
\text { strength, MPa }\end{array}$ & $\begin{array}{c}\text { Tensile } \\
\text { strength, MPa }\end{array}$ \\
\hline S1 & 50.7 & 7.15 \\
\hline S2 & 43.1 & 6.32 \\
\hline S50 & 40.7 & 4.10 \\
\hline S100 & 36.6 & 4.15 \\
\hline
\end{tabular}

Table 10: Mechanical properties (after 28 days)

The results show that S2 mixture has lower strength in compression and tension than S1 mixture. The structure of a split S2 sample is shown in Fig. 7.Another potential drawback of steel punching is corrosion that should be tested in further researches.

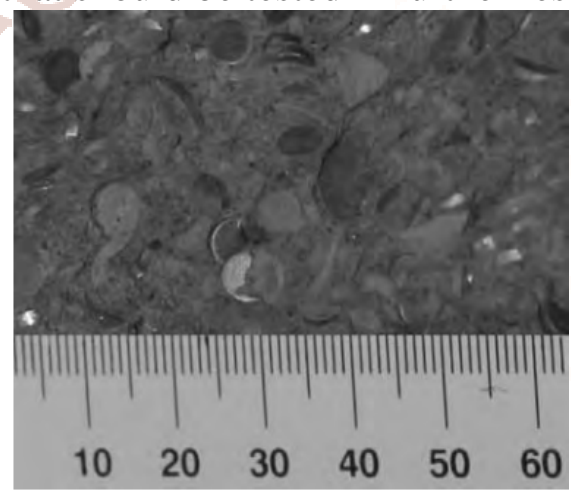

Figure 7: Structure of S2 mixture sample

The research by Kan, Pie and Chang (2004) reveals that the elastic modulus of heavy concrete is higher than for the regular concrete mortar. Moreover, it is 
increasing with the increase of iron ore. As shown in Fig. 8, heavy aggregate inclusion of $48.8 \%$ in the volume makes the elastic modulus of concrete raise

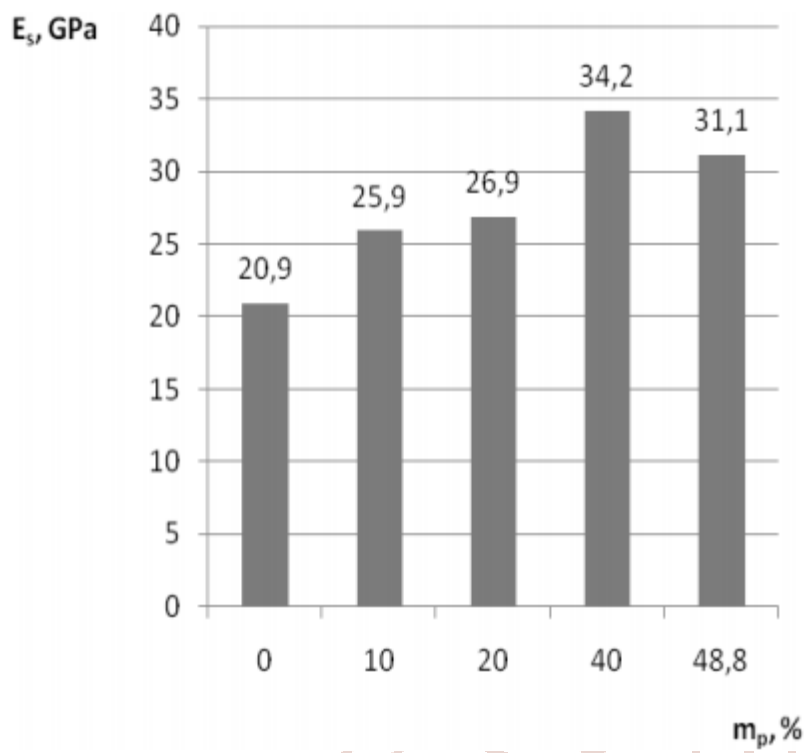

Figure 8: Modulus of elasticity for concrete with various metallic aggregates approximately 1.5 times that of regular mortar.

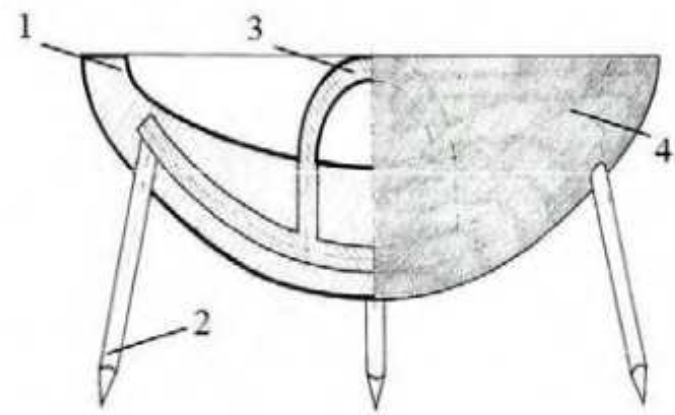

Figure 9: Construction scheme of anchor $(1-$ heavy concrete body, 2 - metal pine, 3 - metal ring, 4 rubber cover).

The rubber cover is used to avoid unfavourable impacts of sea water and possible corrosion. In this study were produced anchor model made of heavy concrete with the density approximately $4300 \mathrm{~kg} / \mathrm{m} 3$ (Fig. 10).

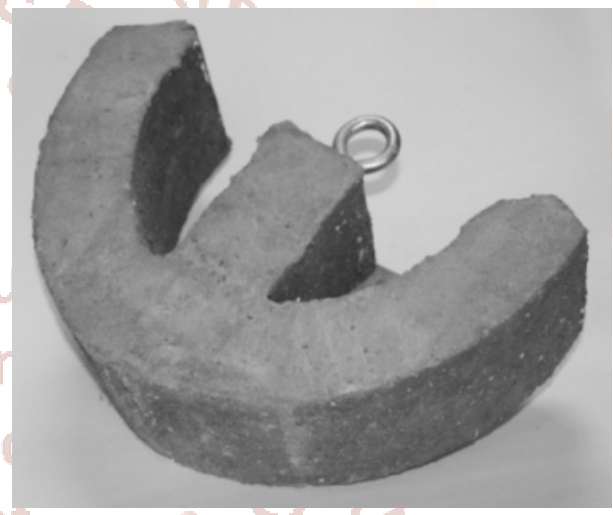

Figure 10: Model

\section{APPLICATION POSSIBILITIES OF HEAVY CONCRETE}

Heavy concrete has high application possibilities in the field of contra weights. The main contra weight material properties are their high density, fine resistance to external environment impacts and low production cost. Contra weights are used to ensure stability of enginery - e.g., machinery, lifts, bridges, floodgates, cranes etc. It is also effective to use heavy concrete in underwater constructions due to its high density that is more notable because of the buoyant force (1), namely, the weight in the water depends on the material mass and density.

Heavy concrete can be used to manufacture the substructure of breakwaters. Another perspective product category includes anchors which would be suitable in fast currents or rocky seafloor. The Institute of Building Production has developed the construction scheme of such anchor that is shown in Fig. 9.
Heavy concrete could also be used as a radiation shielding material in nuclear stations and buildings with heightened radiation level. There are two types of radiation:

1. X-rays and gamma rays. According to the Compton scattering effect, the attenuation efficiency is approximately proportional to the mass of the material used in the shield of radiation. Also, researches confirm that the attenuation coefficient depends on the density of the concrete (Ismail and Al-Hashmi, 2008).

2. Neutrons. An efficient neutron-occluding material consists of heavy elements such as iron the atomic mass of which is 56 and light elements, preferably, hydrogen (Mehta and Monteiro, 2006).

The structure of heavy concrete conforms to both types of radiation attenuation requirements. In addition, heavy concrete has a decent compressive strength, and thus it is usable as a supporting structure. Bore could be used as filler in concrete in order to better attenuate the radiation. 


\section{CONCLUSION}

\section{CHAPTER V}

As planned, the iron containing waste materials heighten the density of product. The highest density obtained in this study is in range $4000-$ $4500 \mathrm{~kg} / \mathrm{m} 3$, though higher density concrete also had greater expenses per mass unit.

$>$ Elastic modulus of heavy concrete is higher than regular concrete mortar and is increasing with the increase of metallic aggregates.

$>$ Optimization of packing was applied to decrease concrete $\mathrm{W} / \mathrm{C}$ ratio and enlarge density.

$>$ Vibration of concrete was used briefly for avoiding of segregation as a result may be issued of metal filler higher specific gravity.

> Potential drawback of steel punching is corrosion that should be tested in further researches.

\section{CHAPTER VI}

\section{REFERENCES}

1. Basyigit C. (2006) The Physical and Mechanical Properties of Heavyweight Concretes Used in Radiation

2. Shielding. Journal of Applied Sciences, Vol. 6, Issue 4, p. 762. - 766.

3. Chundelly R., Greeno R. (2001) Building Construction Handbook. Britsh Library Catalogue in Publication Data. 347 p.

4. Höganäs A B (2010) Iron Powders for Sintered Components [online] [accessed on 30.04.2011.].

5. Available: http://www.hoganas.com/Documents/Brochures/Ir
on_Powders_for_Sintered_Components_ November_2010_web.pdf

6. Höganäs A B (2010) Overview of Powder Grades [online] [accessed on 30.04.2011.]. Available:http://www.hipih.com/cgishl/DC_Show_File.exe?fileId=2257\&btnId=50\&i sWebSiteItem $=1 \&$ save $=0$

7. Ismail Z Z, Al-Hashmi E A. (2008) Reuse of waste iron as a partial replacement of sand in concrete. Waste Management, Vol. 28, Issue 11, p. 2048. -2053.

8. Kan Y. C., Pie K. C., Chang C. L. (2004) Strength and Fracture Toughness of Heavy Concrete with Various Iron Aggregate Inclusions. Nuclear Engineering and Design, Vol. 228, Issues 1-3, p. $119-127$.

9. Kazjonovs J., Bajare D., Korjakins A. (2010) Designing of High Density Concrete by Using Steel Treatment Waste. The 10th international Conference Modern building materials, structures and techniques, Lithuania, Vilnius, p. 138 - 142.

10. Lorente A., Gallegoa E., Vega - Carrillob H. R., Mendez R. (2008) Neutron Shielding Properties of a New High - Density Concrete. 12th International Congress of the International Radiation Protection Association, IRPA-12, Buenos Aires, Argentina, p. $1-10$.

11. Mehta P., Monteiro P. (2005) Concrete Microstructure, Properties, and Materials. New York: McGraw -Hill Professional. 261 - 262 p., $528-530 \mathrm{p}$. 